Revista Complutense de Historia de América

ISSN: $1132-8312$

http://dx.doi.org/10.5209/RCHA.56734

\title{
Fuerzas armadas y militarización de los guardias nacionales en la frontera sur de Argentina (provincia de Buenos Aires, 1862-1879)
}

\author{
Leonardo Canciani ${ }^{1}$
}

Recibido: 29 de octubre de 2015 / Aceptado: 20 de abril de 2016

Resumen. En este artículo se examina cómo el Estado nacional argentino logró monopolizar el control de las fuerzas armadas en la frontera sur del país, a partir de analizar el aporte de cada una de ellas al sistema militar ofensivo/defensivo fronterizo y la militarización de los hombres adultos de la campaña bonaerense en edad militar sujetos al reclutamiento en la Guardia Nacional activa.

Palabras clave: Militarización; frontera sur; Guardia Nacional; Buenos Aires; siglo XIX.

\section{[en] Armed Forces and Militarization of the National Guards on the Southern Border of Argentina (Buenos Aires province, 1862-1879)}

\begin{abstract}
In this paper we analyse how the Argentine State managed to monopolize control of the armed forces along the nation's southern border, by studying the contribution of each force to the offensive/defensive frontier military system and the militarization of adult men, of recruitment age for the active National Guard, in the countryside of the Province of Buenos Aires.
\end{abstract}

Keywords: Militarization; Southern Border; National Guard; Buenos Aires; XIX Century.

Sumario. 1. Introducción. 2. Ejército de Línea, Guardia Nacional e "indios amigos" en la frontera. 3. El servicio de frontera: "una obligación injusta"... ¿e inequitativa?. 4. Conclusiones. 5. Referencias bibliográficas. 6. Anexos.

Cómo citar: Canciani, L. (2017) Fuerzas armadas y militarización de los guardias nacionales en la frontera sur de Argentina (provincia de Buenos Aires, 1862-1879), en Revista Complutense de Historia de América 43, 259-283.

\section{Introducción}

En Argentina, el Estado nacional se consolidó a fines de 1880, luego de siete décadas de conflictos internos y guerras externas ${ }^{2}$. Según se ha sostenido, antes que lograr el consenso necesario para legitimar el nuevo orden político, los liberales que llevaron

\footnotetext{
1 Centro de Estudios Sociales de América Latina, Universidad Nacional del Centro de la Provincia de Buenos Aires (Argentina).

Consejo Nacional de Investigaciones Científicas y Técnicas (Argentina)

E-mail: lcanciani@fch.unicen.edu.ar

2 Míguez, 2003.
} 
a cabo la construcción del Estado estuvieron dispuestos a utilizar la fuerza para lograr sus objetivos y debieron imponer su autoridad por intermedio de la amenaza o el uso de las armas ${ }^{3}$. A lo largo de ese período, el Estado nacional adquirió su propia entidad y se convirtió en el centro del escenario político ${ }^{4}$. Sin embargo, nuevas lecturas enfocadas en las situaciones provinciales mostraron que la centralización estatal no fue sólo una consecuencia de las políticas impuestas de forma unidireccional desde un centro de poder, sino que también fue negociada y buscada por sectores de las elites locales 5 .

Estudiar la construcción estatal desde un enfoque militar-provincial, puntualizando en el abordaje de la Guardia Nacional, puede contribuir a complejizar la explicación del proceso de formación de los estados nacionales y de la conflictiva construcción del vínculo Nación-provincia. En especial, en lo referente a las tensiones que se generaban por las incumbencias militares y el control de la violencia, que en parte todavía están teñidas por una interpretación gradual de la monopolización del uso de la fuerza en manos de una instancia estatal centralizada ${ }^{6}$. En este esquema, Estado y Ejército de Línea fueron vistos como "dos realidades consubstanciales" "7. Este último se erigió como la principal fuerza con la que aquel penetró de forma represiva en las provincias y ejerció un control coactivo en el territorio bajo su jurisdicción. Por su parte, la Guardia Nacional fue vista como la fuerza local con la cual las provincias pudieron defender su autonomía del gobierno central y, al mismo tiempo, como un obstáculo para la formación del Ejército Nacional, ya que estuvo propensa a ser utilizada por los caudillos provinciales y/o regionales que se rebelaban contra la autoridad nacional. Aunque, también sirvió a los objetivos del gobierno, al participar de la expansión de la frontera y combatir a las montoneras del interior del país ${ }^{8}$. Por lo tanto, en este marco interpretativo, la consolidación de los Estados nacionales, en las décadas finales del siglo XIX, habría conllevado a la paulatina desaparición de las milicias y de la Guardia Nacional, a la profesionalización de la oficialidad con técnicas europeas y al fortalecimiento de las instituciones militares centralizadas 9 . Los nuevos aportes de la historiografía están mostrando que dicho proceso no debe interpretarse de forma lineal y acumulativa, ya que a lo largo del siglo XIX las milicias constituyeron una fuerza armada visible y dinámica, que coexistió con el Ejército regular y que, a veces, fue vista como una alternativa más adecuada para la vida republicana ${ }^{10}$.

Para problematizar esta cuestión, es necesario acercarse al tema a través de estudios más específicos, que se circunscriban a territorios concretos. Debido a que la Guardia Nacional ha sido asociada al nivel provincial/local de organización estatal y militar, constituye un terreno óptimo para evaluar la relación Ejército de Línea/ milicias durante la construcción del Estado nacional. El gobernador autorizaba la movilización de contingentes hacia la frontera, promulgaba leyes y sancionaba de-

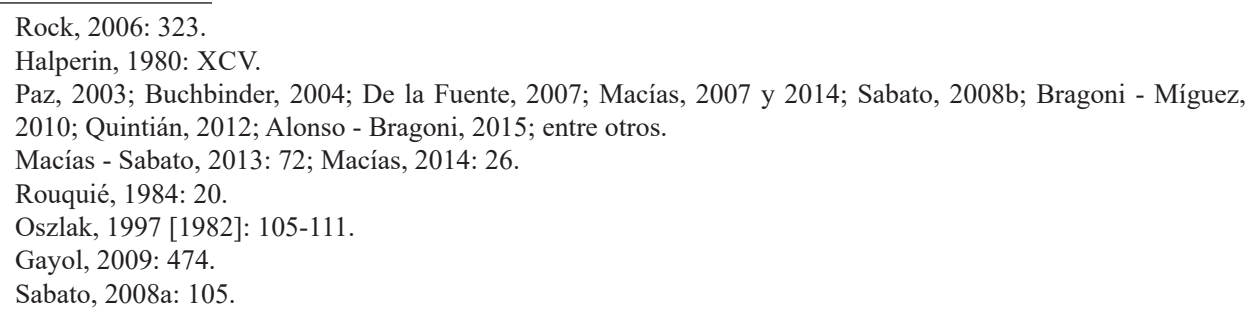


cretos que debieron regir su funcionamiento, designaba a los comandantes de los regimientos y batallones, nombraba a los oficiales que recomendaban estos últimos, entre otras atribuciones ${ }^{11}$. Aunque, también, se ha mostrado la influencia que tuvieron los poderes locales de la campaña y la frontera en el manejo de esta milicia, que la utilizaron de acuerdo a sus intereses políticos y económicos. En determinados momentos, estos se correspondieron con los del Estado provincial, mientras que en otros fueron diferentes, por lo cual no se podría identificar de forma inequívoca a la Guardia Nacional con el gobernador ${ }^{12}$.

En concordancia con estas consideraciones, la propuesta de este artículo es analizar la militarización ${ }^{13}$ de los territorios fronterizos durante el proceso de centralización del poder estatal y examinar el impacto de la misma en los habitantes rurales sujetos al reclutamiento en la Guardia Nacional ${ }^{14}$. Como recorte, tomaremos la frontera de la provincia de Buenos Aires entre 1862 y 1879. Estos años coinciden con la avanzada militar final sobre las tierras pampeanas y norpatagónicas. Se inicia con la unificación definitiva del país, en 1862, que uniformó las políticas de Estado respecto a los indígenas, y finaliza con la campaña del general Julio A. Roca, quien llevó la frontera sur del país hasta los ríos Negro y Neuquén, en mayo de 1879, y libró a los guardias nacionales bonaerenses del servicio de frontera. Durante las presidencias de Bartolomé Mitre (1862-1868), Domingo Sarmiento (1868-1874) y Nicolás Avellaneda (1874-1880) se llevaron a cabo una serie de avances militares progresivos que se acompañaron de medidas tendientes a mantener la paz con los indígenas, con el propósito de evitar conflictos de envergadura. En este contexto, la provincia de Buenos Aires se convirtió en el centro de la expansión fronteriza del país, ya que reunió la mayor cantidad de jefaturas y comandancias militares y aglutinó un alto porcentaje de hombres armados ${ }^{15}$.

El artículo se divide en dos partes. En la primera, examinaremos el aporte de cada una de las fuerzas armadas del Estado a la defensa y expansión de la frontera bonaerense, con el propósito de revisar la periodización que predomina en la historiografía argentina con respecto a la prestación militar de la Guardia Nacional. Para ello, recurriremos a los estados generales realizados por la Inspección y Comandancia General de Armas, que se encuentran en las Memorias del Ministerio de Guerra y Marina de la Nación de 1864 a 1879 (en adelante MMGyM), y a la Memoria de la Inspección General de Milicias de la provincia de Buenos Aires de 1867 (en adelante MIGM). En la segunda parte, procuraremos medir la presión militar a la cual fueron sometidos los regimientos de la Guardia Nacional de la campaña y la frontera, así

Oszlak, 1997 [1982]; Macías, 2001 y 2007; Sabato, 2008a y 2008 b.

12 Canciani, 2017: 363.

13 Entendemos por militarización a la movilización militar de la población sujeta a reclutamiento en el Ejército y en las milicias y a la consecuente multiplicación de unidades militares y milicianas. Halperin, 1968.

14 De acuerdo con Alejandro Rabinovich, creemos conveniente diferenciar la militarización "permanente" de la "intermitente". La primera implicaba a los cuerpos regulares o de Línea, conformados por soldados que hacían de la vida militar una ocupación, y la segunda a los de milicias o de Guardias Nacionales, integrados por civiles movilizados para el servicio de armas por tiempos cortos y en determinadas circunstancias. Rabinovich, 2012: $18-19$.

15 Entre 1862 y 1879 , el Estado nacional erigió una serie de jefaturas y comandancias militares en aquellas provincias que tenían frontera con poblaciones indígenas que no se le habían sometido. En la frontera sur del país, se establecieron seis en Buenos Aires, una en Santa Fe y una en Córdoba, San Luis y Mendoza. Por su parte, en la frontera noreste o chaqueña, se radicó una que aglutinaba a las provincias de Santa Fe, Córdoba, Santiago del Estero y Salta. 
como el nivel de militarización de los milicianos que los integraban. En este caso, apelaremos a los estados generales de la Guardia Nacional de Buenos Aires de 1865 y 1867. Entrecruzaremos los datos de estos registros con los que nos aportan las fuentes mencionadas anteriormente. A su vez, utilizaremos informes y partes militares en los cuales se describen determinados aspectos del servicio de armas en la frontera.

\section{Ejército de Línea, Guardia Nacional e "indios amigos" en la frontera}

Las décadas de 1860 y 1870 constituyeron la etapa más dinámica de la expansión militar de la frontera sur de Argentina. Las autoridades nacionales decidieron ocupar los ríos Negro y Neuquén y, como consecuencia, incorporar una gran extensión de territorio disponible para la ganadería extensiva. La organización militar-miliciana estuvo ligada íntimamente a la frontera, con el propósito de generar una "articulación defensiva"16 entre el Ejército de Línea, la Guardia Nacional y los "indios amigos"17.

El cuidado de la frontera era competencia del gobierno nacional y, por lo tanto, del Ejército de Línea. Según se ha sostenido, durante los años de "organización nacional", esta fuerza proveyó la mayor cantidad de efectivos permanentes para guarnecer ese territorio ${ }^{18}$. Sin embargo, en ciertas coyunturas, la Guardia Nacional tuvo una presencia relevante y relegó a los cuerpos regulares a un segundo plano. En este sentido, existe consenso entre los historiadores en que durante la participación de la Argentina en la Guerra de la Triple Alianza (1865-1870), la vigilancia, defensa y expansión de las fronteras sur y noreste del país se recostaron en los regimientos de la Guardia Nacional, debido a que los soldados regulares fueron destinados a combatir en Paraguay ${ }^{19}$. La presencia del Ejército de Línea habría sido más notoria durante la década de $1870^{20}$, a medida que se iba reduciendo la implicancia de la Guardia Nacional y se incrementaba la de los "indios amigos" 21 . Esta situación se habría profundizado a partir de 1876, cuando las fuerzas regulares se hicieron cargo de la definitiva expansión de la frontera sur, al haber finalizado los levantamientos militares en el Interior del país ${ }^{22}$.

Como ha señalado Alejandro Rabinovich, estudiar la militarización a partir de la cantidad de efectivos que sirvieron en las fuerzas armadas tiene la ventaja de ofrecer un elemento cuantificable que nos permitiría comprender más ajustadamente la presión militar sobre la población y los modos en que la organización del Ejército pudo

16 Alemano - Carlón, 2009: 40-41.

17 Para el Ejército de Línea, véase Comando en Jefe del Ejército, 1971-1972; Garavaglia, 2003; Olmedo, 2009; para el servicio de frontera de la Guardia Nacional, Barbuto, 2009; Literas, 2012; Canciani, 2014; y para la prestación militar de los "indios amigos", Ratto, 2003; Tamagnini - Pérez - Olmedo, 2009; Gambetti, 2012.

18 Walther, 1964.

19 Walther, 1964; Ratto, 2011; Gambetti, 2012; Canciani, 2013. La Guardia Nacional fue creada con la intensión de "dar para el porvenir una custodia fiel y firme al tesoro precioso de las Leyes y [...] un apoyo fuerte a la autoridad legítimamente constituída". No englobaba la guarda de la frontera y la defensa de los intereses rurales. Por lo tanto, el Congreso de la Nación debió sancionar una serie de leyes para investir de legalidad a dicho servicio y autorizar al Poder Ejecutivo para movilizar contingentes de guardias nacionales de las provincias. Para más información, véase Literas, 2012.

20 Barba, 1976; Oszlak, 1997 [1982].

21 Ratto, 2011; Gambetti, 2012.

22 Walther, 1964. 
haber influido en la conformación del Estado ${ }^{23}$. Pero, realizar una contabilización exhaustiva de las fuerzas armadas que operaron en la frontera bonaerense conlleva una serie de inconvenientes metodológicos y conceptuales difíciles de resolver.

Primero, carecemos de datos completos para los años 1862, 1863 y 1867, lo que reduce la posibilidad de obtener conclusiones contundentes para todo el período estudiado. Segundo, los detalles de las MMGyM y de la MIGM fueron elaborados en base a informes y listas de revista enviados a la Inspección General de Armas por los jefes de frontera y, como ya sabemos, en ocasiones esos números podían ser fraguados, al aumentar la cantidad de hombres en servicio, con el propósito de recibir pagas extras ${ }^{24}$. Tercero, la información que nos provee el estado de las fuerzas armadas no representa a la totalidad del año, sino que sólo muestra la situación existente en determinados meses, por lo general marzo o abril. Por lo tanto, los datos que exponemos en las tablas y los gráficos no evidencian la dinámica del sistema militar-miliciano en la frontera, sino su estado en un momento determinado. A causa de ello, la información que reconstruimos sobre las fuerzas de Línea, de la Guardia Nacional y de los "indios amigos" tiene un carácter provisorio y sólo puede tomarse de forma preliminar.

Los soldados hicieron de la vida militar una profesión y sirvieron regularmente. Pero, ello no significó que se mantuvieran de forma permanente en la frontera, ya que podían ser trasladados a cualquier lugar del país que dispusieran los mandos superiores e, incluso, fuera de Argentina, como sucedió durante la guerra contra Paraguay. Por su parte, los contingentes de la Guardia Nacional se enviaron asiduamente a la frontera, ante la insuficiencia del Ejército de Línea, sólo por 6 meses, cumplidos los cuales debían ser relevados por otros. Si este reclutamiento hubiera funcionado de acuerdo a las reglamentaciones militares, podríamos inferir que, a lo largo del año, el número de guardias nacionales enviados a la frontera de forma regular duplicaría el que presentamos en la Tabla 1. Pero ello no fue así. Sabemos que no todos los milicianos cumplieron un servicio de 6 meses, ya que algunos lo hicieron por menos tiempo y otros por más, al ser extendido, de forma arbitraria, por los jefes de las comandancias ${ }^{25}$.

Por último, al igual que se ha mostrado para los "indios amigos" 26 , los datos de las MMGyM omiten la cantidad de guardias nacionales movilizados circunstancialmente para defender la frontera. Si contemplamos a los que fueron militarizados sólo por el lapso de días o de pocas semanas, la importancia de los vecinos de la campaña en el sistema militar ofensivo/defensivo se incrementa aún más.

\footnotetext{
Rabinovich, 2012: 17.

Barros, 1957 [1872]: 166 y 185; Poggi, 1997: 13.

Canciani, 2014: 43-46.

Ratto, 2011; Gambetti, 2012.
} 
Tabla 1. Fuerzas establecidas en la frontera de Buenos Aires (1864-1879) ${ }^{27}$

\begin{tabular}{|c|c|c|c|c|c|c|c|}
\cline { 2 - 8 } \multicolumn{1}{c|}{} & \multicolumn{2}{|c|}{ Ejército de Línea } & \multicolumn{2}{c|}{ Guardia Nacional } & \multicolumn{2}{c|}{ "Indios amigos" } & Total \\
\hline Año & $\mathbf{n}^{\circ}$ & $\mathbf{\%}$ & $\mathbf{n}^{\circ}$ & $\mathbf{\%}$ & $\mathbf{n}^{\circ}$ & $\mathbf{\%}$ & $\mathbf{n}^{\circ}$ \\
\hline $\mathbf{1 8 6 4}$ & 3.205 & $71,35 \%$ & 891 & $19,84 \%$ & 396 & $8,81 \%$ & $\mathbf{4 . 4 9 2}$ \\
\hline $\mathbf{1 8 6 5}$ & 2.714 & $73,51 \%$ & 599 & $16,22 \%$ & 379 & $10,27 \%$ & $\mathbf{3 . 6 9 2}$ \\
\hline $\mathbf{1 8 6 6}$ & 730 & $21,9 \%$ & 1.976 & $59,27 \%$ & 628 & $18,83 \%$ & $\mathbf{3 . 3 3 4}$ \\
\hline $\mathbf{1 8 6 7}$ & sin datos & sin datos & 1.637 & - & sin datos & sin datos & $\mathbf{1 . 6 3 7}$ \\
\hline $\mathbf{1 8 6 8}$ & 812 & $31,23 \%$ & 1.428 & $54,92 \%$ & 360 & $13,85 \%$ & $\mathbf{2 . 6 0 0}$ \\
\hline $\mathbf{1 8 6 9}$ & 1.112 & $46,66 \%$ & 906 & $38,02 \%$ & 365 & $15,32 \%$ & $\mathbf{2 . 3 8 3}$ \\
\hline $\mathbf{1 8 7 0}$ & 1.302 & $51,20 \%$ & 930 & $36,57 \%$ & 311 & $12,23 \%$ & $\mathbf{2 . 5 4 3}$ \\
\hline $\mathbf{1 8 7 1}$ & 2.275 & $50,36 \%$ & 1.930 & $42,73 \%$ & 312 & $6,91 \%$ & $\mathbf{4 . 5 1 7}$ \\
\hline $\mathbf{1 8 7 2}$ & 1.967 & $61,53 \%$ & 917 & $28,68 \%$ & 313 & $9,79 \%$ & $\mathbf{3 . 1 9 7}$ \\
\hline $\mathbf{1 8 7 3}$ & 2.194 & $65,85 \%$ & 810 & $24,31 \%$ & 328 & $9,84 \%$ & $\mathbf{3 . 3 3 2}$ \\
\hline $\mathbf{1 8 7 4}$ & 2.211 & $49,14 \%$ & 1.785 & $39,68 \%$ & 503 & $11,18 \%$ & $\mathbf{4 . 4 9 9}$ \\
\hline $\mathbf{1 8 7 5}$ & 2.478 & $64,08 \%$ & 472 & $12,21 \%$ & 917 & $23,71 \%$ & $\mathbf{3 . 8 6 7}$ \\
\hline $\mathbf{1 8 7 6}$ & 3.972 & $60,12 \%$ & 1.646 & $24,91 \%$ & 989 & $14,97 \%$ & $\mathbf{6 . 6 0 7}$ \\
\hline $\mathbf{1 8 7 7}$ & 3.507 & $58,75 \%$ & 1.718 & $28,78 \%$ & 744 & $12,47 \%$ & $\mathbf{5 . 9 6 9}$ \\
\hline $\mathbf{1 8 7 8}$ & 3.561 & $86,18 \%$ & 0 & $0 \%$ & 571 & $13,82 \%$ & $\mathbf{4 . 1 3 2}$ \\
\hline $\mathbf{1 8 7 9}$ & 3.073 & $86,49 \%$ & 0 & $0 \%$ & 480 & $13,51 \%$ & $\mathbf{3 . 5 5 3}$ \\
\hline Total & $\mathbf{3 5 . 1 1 3}$ & $\mathbf{5 8 , 1 8 \%}$ & $\mathbf{1 7 . 6 4 5}$ & $\mathbf{2 9 , 2 4 \%}$ & $\mathbf{7 . 5 9 6}$ & $\mathbf{1 2 , 5 8 \%}$ & $\mathbf{6 0 . 3 5 4}$ \\
\hline
\end{tabular}

Gráfico 1. Fuerzas establecidas en la frontera de Buenos Aires en cantidad ${ }^{28}$

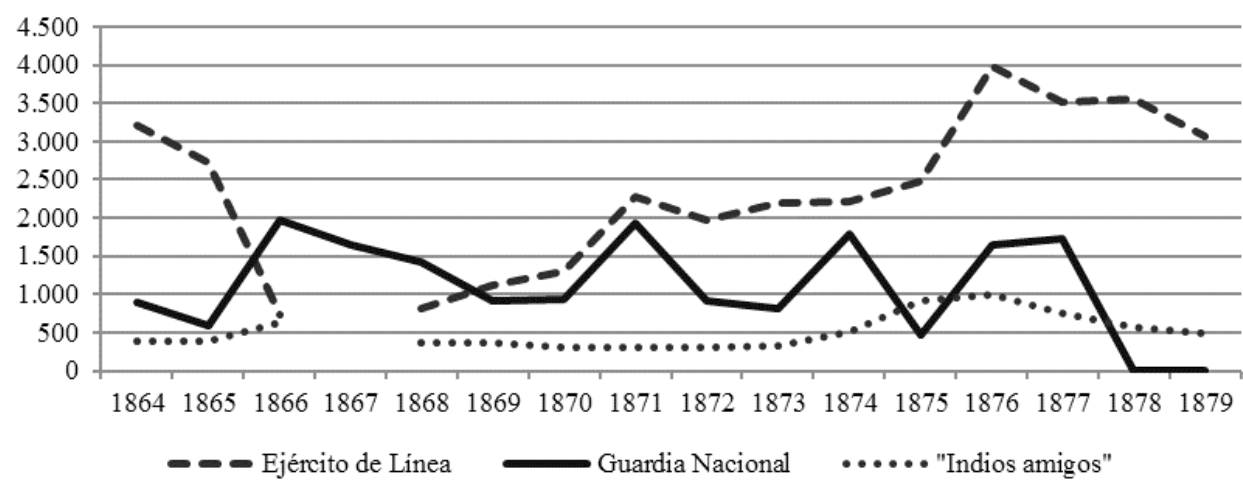

27 Fuente: elaboración propia en base a las MMGyM de 1864-1879 y a la MIGM de Buenos Aires de 1867. Archivo Histórico de la Provincia de Buenos Aires [Argentina] (en adelante AHPBA), Ministerio de Gobierno, año 1867 , leg. 3, exp. 238.

28 Fuente: elaboración propia en base a las MMGyM de 1864-1879 y a la MIGM de Buenos Aires de 1867 (AHPBA, Ministerio de Gobierno, año 1867, leg. 3, exp. 238). 
Gráfico. 2. Fuerzas establecidas en la frontera de Buenos Aires en porcentaje ${ }^{29}$

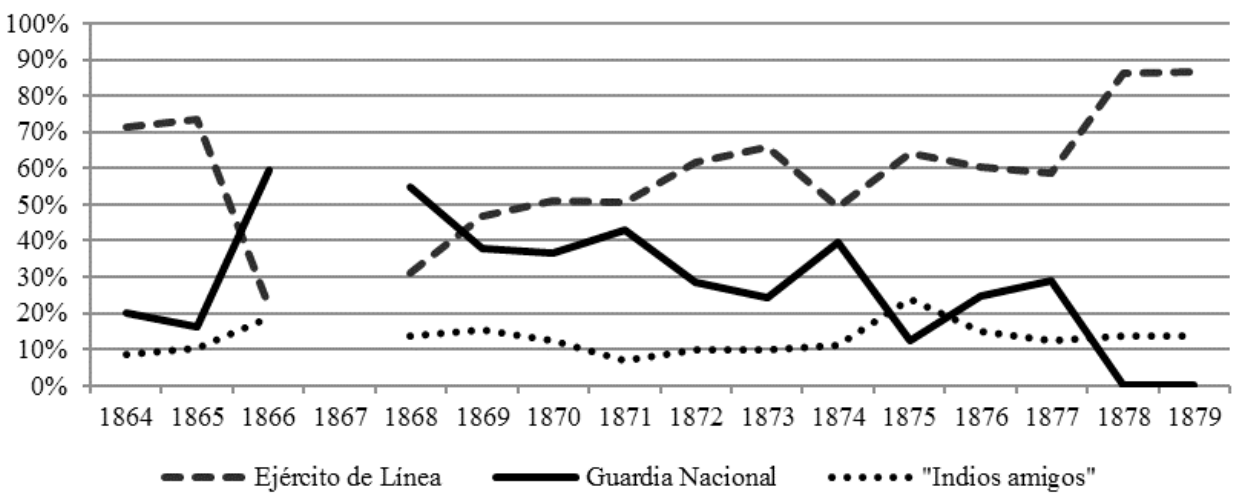

Según la información que vertimos en la Tabla 1 y en los gráficos 1 y 2, a lo largo del período 1864-1879, el Ejército de Línea aportó la mayor cantidad de plazas fijas para la frontera bonaerense. Del total de 60.354 hombres que registramos ${ }^{30}$, éste suma $35.113(58,18 \%)$, la Guardia Nacional $17.645(29,24 \%)$ y los "indios amigos" $7.596(12,58 \%)$.

Al examinar con mayor profundidad, se disciernen diferentes períodos. En primer lugar, previo al estallido de la Guerra de la Triple Alianza ${ }^{31}$, se observa un notable predominio de las fuerzas regulares, que superaban el $70 \%$ de los efectivos, sobre la Guardia Nacional y los "indios amigos", que no alcanzaban el 20\% y 10\% del total, respectivamente. Si bien no contamos con datos precisos para 1862 y $1863^{32}$, estimamos que el peso de la Guardia Nacional en la defensa de la frontera debe haber sido mayor que en 1864 y los primeros meses de 1865, debido a que parte de los regimientos de caballería y de los batallones de infantería del Ejército regular habían marchado, con sus jefes, al interior del país a neutralizar los levantamientos y las montoneras, así como acabar con las reacciones a los vencedores de la batalla de "Pavón". La creación del Ejército de Línea, en base a las fuerzas militares de Buenos Aires, en 1864, y la reducción de conflictos militares en el territorio nacional conllevaron al licenciamiento de algunos guardias nacionales que estaban en la frontera.

En segundo lugar, con el envío de fuerzas militares a la guerra contra Paraguay, desde abril y mayo de 1865 , se redujo la cantidad de efectivos acantonados en la frontera bonaerense. En 1866, apenas superaron los 3.500 y en 1868, 1869 y 1870 descendieron a $2.600,2.383$ y 2.543 , respectivamente. Durante este lustro, la reducción de las fuerzas en la frontera se correspondió con una menor cantidad de efecti-

29 Fuente: elaboración propia en base a las MMGyM de 1864-1879 y a la MIGM de Buenos Aires de 1867 (AHPBA, Ministerio de Gobierno, año 1867, leg. 3, exp. 238).

30 Registramos a los jefes, oficiales, tropa y colaboradores que sirvieron en las fronteras Norte, Oeste, Sud y Costa Sud y en las comandancias militares de San Nicolás, Bahía Blanca y Patagones.

31 Al momento de realizarse la MMGyM de 1865, todavía no se habían enviado los efectivos de Línea a Paraguay, hecho que se produjo a partir del mes de abril.

32 Para 1862, no tenemos datos relativos a las fuerzas que operaron en la frontera bonaerense, ya que la primera MMGyM data de 1863. La Memoria de este año informa que se habían movilizado 1.870 guardias nacionales, con 120 oficiales, y 387 "indios amigos" para todo el territorio nacional, por lo que no podemos discernir las que correspondieron solo a la frontera de Buenos Aires. 
vos de Línea y un consecuente incremento de guardias nacionales e "indios amigos". En 1866 y 1868, la Guardia Nacional proveyó la mayor parte de los hombres de la frontera, a punto de rozar el 60\% y el 55\%, respectivamente. Si bien para 1867 no se disponen de datos de las otras fuerzas, su presencia fue inferior al año anterior y superior al siguiente en términos nominales. Por su parte, el Ejército de Línea sólo registró entre el $20 \%$ y el $30 \%$ de las plazas. Sin embargo, a medida que fueron regresando de Paraguay, los cuerpos regulares volvieron a ocupar espacios importantes en el sistema defensivo fronterizo y proveyeron la mayor cantidad de unidades, aunque no muy lejos de la Guardia Nacional. Por último, los "indios amigos" fueron reduciendo progresivamente su participación durante la guerra, aunque nunca con valores inferiores al 12\%, incluso, superando el $18 \%$ en 1866 .

En tercer lugar, en 1871-1873, se incrementa de forma paulatina el aporte del Ejército regular $(50,36 \%, 61,53 \%$ y $65,85 \%$, respectivamente), mientras que la Guardia Nacional fue perdiendo su lugar (42,73\%, 28,68\% y 24,31\%). Los lanceros indígenas registraron prácticamente la misma cantidad de plazas que en los años anteriores, aunque en términos porcentuales su participación fue creciendo: 312 $(6,91 \%), 313(9,79 \%)$ y $328(9,84 \%)$.

Sin embargo, esta tendencia se aminoró en 1873-1874, como consecuencia de las exigencias militares del segundo levantamiento de Ricardo López Jordán ${ }^{33}$. Si bien no se redujo la cantidad de fuerzas regulares -de hecho se incrementaron en 17 unidades, alcanzando la suma de 2.211 hombres- en términos porcentuales se registra una notoria merma. El Ejército de Línea no alcanza a cubrir el 50\% de los efectivos y, en su lugar, la Guardia Nacional computa la importante suma de 1.785 plazas, que roza el 40\%. En este contexto, debemos insertar el decreto del 31 de mayo de 1873 del gobernador de Buenos Aires, Mariano Acosta, por el cual dispuso la movilización de 1.800 guardias nacionales para guarnecer las fronteras Norte, Oeste y Sud de esa provincia ${ }^{34}$. Los lanceros indígenas también se incrementaron con respecto a los años anteriores, iniciando una tendencia que se mantendrá hasta fines de la década. Suman 503, que representaron el 11,18\%.

En cuarto lugar, en la segunda mitad de la década de 1870, el Ejército de Línea consolidará de forma definitiva su predominio sobre las demás fuerzas armadas. En términos nominales, hasta 1876 mantendrá el aumento continuo que había iniciado en 1872, alcanzando en aquel año el pico de todo el período 1864-1879, con 3.972 efectivos. A partir de entonces, esa cantidad se irá reduciendo, aunque mantendrá altos niveles, al superar la barrera de los 3.000 hombres, a la cual solamente se había llegado en 1864. Por su parte, en términos porcentuales, la situación es cambiante y se explica por las variaciones en el aporte de la Guardia Nacional y los soldados indígenas. Durante 1875, su nivel vuelve a aumentar, hasta superar el 64\%; aunque, nuevamente, se reducirá de forma progresiva en el siguiente bienio hasta el 58,75\%. Finalmente, en 1878 y 1879, su lugar se incrementa de forma notable, ya que supera el $86 \%$ del total.

\footnotetext{
33 Ricardo López Jordán, se rebeló contra el gobierno nacional en tres ocasiones: 1870-1871, 1873 y 1876. En las dos primeras, el presidente Domingo F. Sarmiento debió movilizar parte de las fuerzas del Ejército de Línea que estaban acantonadas en la frontera para reducir las milicias de Entre Ríos comandadas por aquel; mientras que en el tercer levantamiento no fue necesario, ya que las fuerzas que estaban en la región lo pudieron frenar a tiempo y apresar a López Jordán. Sabato, 2012: 215-220.

34 Domínguez, 1898: 438.
} 
El caso de los "indios amigos" es más complejo. De acuerdo con Silvia Ratto y Nadia Gambetti, a partir de 1874 se observa un incremento nominal evidente con respecto a los años anteriores. Sin embargo, los niveles porcentuales no varían demasiado si se comparan con los registrados para 1866-1870, que oscilaron entre el $12 \%$ y el 19\%. Sí superan los del primer lustro de la década de 1870 , que, en pocos casos, pudieron sobrepasar la barrera del 10\%. El valor más alto se observa en 1875, cuando alcanzaron el $23,71 \%$, y en los próximos cuatro años se mantienen en una franja que varía entre el $12 \%$ y el $15 \%$. A medida que nos acercamos al final de este decenio, fueron sólo los lanceros indígenas quienes cubrieron las falencias del Ejército regular, como consecuencia del relevo definitivo de la Guardia Nacional de Buenos Aires del servicio de frontera.

Por último, en lo que respecta a esta fuerza miliciana, en 1875 se registraron 472 plazas $(12,21 \%)$, que fueron casi duplicadas por "los indios amigos". En este contexto, el 14 de diciembre de 1875, a instancias del ministro de Guerra y Marina de la Nación, Adolfo Alsina, el presidente Nicolás Avellaneda decretó el licenciamiento de toda la Guardia Nacional que existía movilizada haciendo el servicio de frontera para el 31 de diciembre de ese año. Los motivos que llevaron a tal disposición fueron tres: haberse cubierto las plazas del Ejército de Línea que autorizaba el presupuesto, que con ellas bastaba para llevar a cabo el servicio ordinario en la frontera y que ya no existía temor de alteración del orden público. Según el reparo del decreto, este último sería el único caso en que "una necesidad imperiosa colocaría al Gobierno en el deber penoso de apelar á la Guardia Nacional de la República" ${ }^{35}$.

Para Fernando Barba, Alsina decidió terminar con el injusto e inconstitucional servicio que prestaba la Guardia Nacional de las provincias argentinas de defender en forma ordinaria y permanente la frontera interior del país. Agregó que para ello realizó un nuevo reclutamiento con el cual completó al Ejército Nacional de tal forma que fuera exclusivamente el que se ocupara, como correspondía, del cuidado de la frontera y de la lucha contra los indígenas ${ }^{36}$. Algunos especialistas, como Oscar Oszlak, acordaron con esta visión, al afirmar que desde 1876, al decretarse el licenciamiento de la Guardia Nacional, el Ejército de Línea había asumido la exclusiva responsabilidad de la actividad militar $^{37}$. Sin embargo, no podemos tomar como ciertas estas afirmaciones, ya que la Guardia Nacional siguió sirviendo en la frontera. Incluso, en 1876 y 1877, sus fuerzas se incrementaron con respecto a los años anteriores.

Varias comunicaciones atestiguan esta situación. El 6 de enero de 1876, a tan sólo 6 días de que hubiera comenzado a regir el decreto en cuestión, el jefe de Frontera Oeste pedía al juez de paz de Bragado que reuniera 150 guardias nacionales con sus caballos ${ }^{38}$. A pocos días, el subinspector de Milicias de la Frontera Costa Sud le informaba al inspector general de Milicias de Buenos Aires que había recibido órdenes de Adolfo Alsina y Nicolás Levalle de que mantuviera reunidos los guardias nacionales que habían sido designados para el servicio de frontera, "que por las comunicaciones oficiales [recibidas] este servicio será permanente largo tiempo"39.

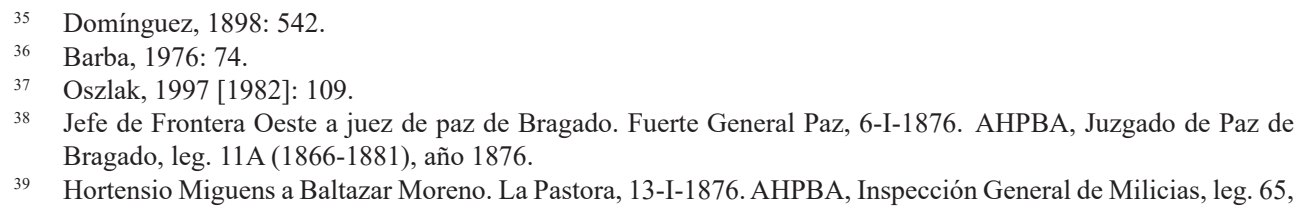


Veinte días más tarde, el ministro de Gobierno de Buenos Aires ordenaba al juez de paz de Bragado recolectar 60 caballos de marcas desconocidas para proveer a los 30 guardias nacionales de ese partido que debían marchar a la frontera ${ }^{40}$. El 9 de agosto de 1876, Adolfo Alsina le solicitaba al gobernador Carlos Casares que contribuyera, para los próximos 6 meses, con 1.500 guardias nacionales, en lugar de los 1.000 que aportaba hasta ese entonces ${ }^{41}$. El 29 de mayo de 1877, el comandante de la Guardia Nacional de Bahía Blanca informaba al ministro de Gobierno que había entregado 100 guardias nacionales al comandante militar de esa guarnición, "con la creencia de que a los seis meses estarían licenciados"42. Finalmente, el 1 de julio de ese año, en la presentación de la MMGyM de la Nación, Alsina reconocía el problema, al sostener que el Ejército de Línea todavía no había cubierto las plazas que necesitaba para defender la frontera y afirmaba que la Guardia Nacional se encargaba del cuidado de su retaguardia ${ }^{43}$.

Además, debemos agregar que el 1 de diciembre de 1877, se decretó un nuevo enrolamiento de toda la Guardia Nacional del país, que se llevaría a cabo entre el 1 de abril y el 30 de junio de 1878, "para los fines de la Constitución y como base de la formación del Ejército de Línea". Concluido dicho enrolamiento, los gobernadores debían remitir para el servicio de frontera a los infractores de la medida y, en caso de que estos no hubieran cubierto las falencias de las fuerzas regulares, debían ser completadas con parte de los enrolados ${ }^{44}$.

De acuerdo con esta información, durante 1876 y 1877 , el aporte de la Guardia Nacional vuelve a ser fundamental. Se registran $1.646(24,91 \%)$ y $1.718(28,78 \%)$ milicianos, respectivamente, que se emplearon en la construcción de un foso sobre el nuevo avance fronterizo -conocido como "Zanja de Alsina"45 - y para cubrir la retaguardia o segunda línea de fortines. La avanzada fue custodiada, en gran parte, por soldados de Línea y, en menor medida, lanceros indígenas y, como consecuencia, la presencia de estos en la segunda línea de fortines fue poco perceptible, sobre todo en 1876. En 1877, el ingeniero francés Alfred Ebelot, que participó del planeamiento del foso, dejó constancia en sus informes que se quisieron emplear alrededor de 800 hombres de la Guardia Nacional que fueron movilizados especialmente para ese fin. Aunque, remarcó que antes de llegar se redujeron a 600. De los que llegaron, dos tercios fueron destinados a la excavación y el resto a diversas tareas del campamento

año 1876 , notas sin numerar.

40 Aristóbulo del Valle a juez de paz de Bragado. Buenos Aires, 16-II-1876. AHPBA, Juzgado de Paz de Bragado, leg. 11A (1866-1881), año 1876.

${ }^{41}$ Adolfo Alsina a Carlos Casares. Buenos Aires, 9-VIII-1876. AHPBA, Ministerio de Gobierno, año 1876, leg. 13, exp. 574.

42 Ángel Marcos a Vicente Quesada. Bahía Blanca, 29-V-1877. AHPBA, Inspección General de Milicias, leg. 76, año 1877 , exp. 213.

43 En la introducción de la mencionada Memoria, Adolfo Alsina sostenía: "Lo que me he propuesto es dejar establecido: $1^{\circ}$ - Que el gobierno, por necesidad, se vé obligado á conservar la Guardia Nacional movilizada para el servicio ordinario de frontera. $2^{\circ}$ - Que esa Guardia Nacional coopera hoy á la ejecución de un plan sério que, llevado á término, será lo único que garanta al habitante de la Campaña, en condiciones estables, su propiedad, su hogar y su reposo". MMGyM, 1877: XIII-XV.

44 Domínguez, 1898: 567-568.

45 Se había proyectado desde Bahía Blanca (extremo sur de Buenos Aires) hasta la frontera sur de Córdoba, debiendo cubrir $610 \mathrm{~km}$, de los cuales sólo se llegaron a construir cerca de $374 \mathrm{~km}$ en territorio bonaerense. Tenía una abertura de 2,60 metros de ancho y una profundidad de 1,75 metros. El propósito del foso fue cerrar el camino a las grandes invasiones y tornar difícil las pequeñas, antes que evitar el ingreso a las tierras recientemente incorporadas. Ébelot, 1968: 111-112; Barba, 1997: 103-104. 
y al servicio personal de los oficiales ${ }^{46}$. Con respecto a este tema, en la MMGyM de 1878 se afirma que fueron 789 los guardias nacionales que se encargaron del zanjeo $\mathrm{y}$, por tal motivo, obtuvieron la excepción de cualquier servicio militar por el término de diez años ${ }^{47}$.

Finalmente, lo que resalta en la Tabla 1 es que no se registran guardias nacionales en la frontera en 1878 y 1879. Según el informe del ministro de Guerra y Marina, Julio A. Roca, "la Guardia Nacional que estaba movilizada en servicio de fronteras ha sido totalmente licenciada" y "removí[do] cuerpos de línea para reemplazar las milicias que aún había en armas en algunos puntos". Con este hecho, agregaba, "el servicio de frontera está exclusivamente atendido por el Ejército de Línea y los indios auxiliares que voluntariamente se han sometido"48. Sin embargo, por una carta del jefe de los regimientos de guardias nacionales de las fronteras Sud y Costa Sud al ministro Roca, sabemos que los guardias nacionales de esos distritos estuvieron en servicio en la frontera al menos hasta mayo de 1878, cuando fueron licenciados ${ }^{49}$.

Esta información tiene correlación, sólo en parte, con los planteos de Silvia Ratto y Nadia Gambetti. Estas autoras advierten que a partir de 1874 se incrementó el aporte militar de los lanceros indígenas al sistema defensivo fronterizo, mientras que disminuyó el de los guardias nacionales ${ }^{50}$. De acuerdo con nuestra investigación, el declive definitivo de la Guardia Nacional no se produjo desde ese año -cuando se registra el tercer mayor aporte en el período estudiado-, sino en los primeros meses de 1878, cuando se redujeron fuertemente sus contingentes, para no existir más en la segunda mitad de ese año. Durante 1876 y 1877, a causa de las actividades que se desarrollaron con el fin de fijar la nueva expansión fronteriza planeada por Adolfo Alsina, la Guardia Nacional volvió a ser convocada, observándose el cuarto y el quinto registros nominales más altos entre 1863-1879. Además, si bien se incrementaron los niveles porcentuales de participación de los lanceros indígenas en las fuerzas de frontera durante la década de 1870, lo cierto es que, desde fines de 1876, se fue reduciendo, de forma progresiva, su aporte nominal. Por lo tanto, planteamos que fueron los soldados del Ejército de Línea, más que los "indios amigos” quienes suplantaron a los guardias nacionales en el servicio de frontera, ya que durante 18761879 aquellos registraron los valores nominales -aunque no siempre porcentuales-, más altos en todo el período que abordamos en esta investigación.

\section{El servicio de frontera: "una obligación injusta"... ¿e inequitativa?}

Luego de mostrar el rol destacado que tuvo la Guardia Nacional en el sistema militar defensivo/ofensivo de la frontera, debemos preguntarnos si el servicio miliciano fue una práctica equitativa para todos los pobladores domiciliados en la provincia o si, en cambio, se intensificó la militarización en los partidos fronterizos. Al mismo tiempo, nos proponemos medir el nivel de militarización de los guardias nacionales enrolados en los regimientos y batallones de la campaña bonaerense.

46 Ébelot, 1968: 131-138.

47 MMGyM, 1878: 33.

48 Ibídem: X.

49 Pedro Muñoz Pérez a Julio A. Roca. Buenos Aires, 15-V-1878. Servicio Histórico del Ejército [Argentina] (en adelante SHE), Frontera con los indios, año 1878, doc. 7.989.

50 Ratto, 2011: 18; Gambetti, 2012: 31-39. 
Desde la década de 1850, las autoridades porteñas se preocuparon de que el servicio de frontera fuera realizado de forma equilibrada. Por intermedio de un Acuerdo del 23 de noviembre de 1858, recomendaron, a los jefes de frontera, que procuraran no recargar siempre a los regimientos de los distritos fronterizos, ya que todos los cuerpos de la campaña estaban obligados a brindarlo ${ }^{51}$. Sin embargo, al parecer, este problema no tuvo una resolución favorable. En 1863, en el marco de los debates que se produjeron en la Cámara de Diputados en torno al servicio de frontera que brindaba la Guardia Nacional, el legislador José Mármol denunciaba la "división profunda [que existía] entre el habitante de la campaña y el de la ciudad"52.

Con el propósito de resolver esta carga desigual, en agosto de 1869 el gobernador bonaerense Emilio Castro decretó el establecimiento del sorteo como mecanismo para la formación de contingentes de guardias nacionales de la campaña que deberían marchar a la frontera. El sorteo se debería realizar en los pueblos cabeceras de partido o, si éste no existiese, en los juzgados de paz. Abarcaría al 7\% de los hombres enrolados en la milicia activa de sus respectivos regimientos y quienes resultasen designados formarían el contingente del distrito que marcharía a la frontera por el término de un año ${ }^{53}$. Sin embargo, pese a su sanción, el decreto no tuvo gran aceptación en la prensa y en los hacendados de la campaña y, por tal motivo, fue suspendido y nunca se implementó ${ }^{54}$.

Incluso, para la década de 1870 este problema siguió aquejando a la formación de contingentes. A inicios de 1876, el subinspector de Guardias Nacionales de la Costa Sud escribía a su superior, el inspector general de Milicias, comunicándole su preocupación por el recargo que se hacía a algunos partidos por el servicio de frontera. Creía que no debía recaer todo el peso sobre uno o varios de ellos, sino reclutar la fuerza de todos los que integraban la Frontera Costa Sud. De esa forma, se atenuarían los problemas que el servicio armado permanente generaba en los establecimientos productivos de la zona. Así lo exponía:

Como estos Partidos, llamados al servicio actual, dieron los contingentes para la Frontera en Mayo del año pasado y hoy vuelven a movilizarse, é creído justo, como le manifesté verbalmente al señor Gobernador, que un contingente de todos los Partidos de mi Sección, no afectará en nada los intereses rurales de los Partidos de la Costa Sud, como sucede, en estos momentos, con los Partidos que tenían movilizada toda la G.N. de ellos y que por las comunicaciones oficiales, este servicio será permanente largo tiempo, creo, llegado el caso de adoptar la medida expresada, de que los contingentes fueran de todo el Departamento de la Costa $\mathrm{Sud}^{55}$.

Por desgracia, la escasez y dispersión de la documentación no nos permiten establecer afirmaciones precisas sobre el nivel del recargo de los regimientos fronterizos

51 Acuerdo para el servicio de los regimientos de Guardias Nacionales de Caballería de Campaña. Buenos Aires, 23-XI-1858. Archivo General de la Nación [Argentina] (en adelante AGN), Comandancia General de Frontera, Fuertes y Fortines, X-19-8-4.

52 Poggi, 2000: 13.

53 Decreto sobre reclutamiento de la Guardia Nacional de frontera de acuerdo al sorteo. Buenos Aires, 10-VIII1869. AHPBA, Inspección General de Milicias, año 1869, doc. 1.577.

54 Canciani, 2017: 218 .

55 Hortensio Miguens a Baltazar Moreno. La Pastora, 13-I-1876. AHPBA, Inspección General de Milicias, leg. 65, notas sin numerar. 
y de la militarización de los guardias nacionales de la provincia de Buenos Aires, como así tampoco arribar a afirmaciones concluyentes para la totalidad del período que abordamos. En cambio, sí podemos plantear algunas conjeturas en base a una serie de datos excepcionales que provienen de las MMGyM de la Nación y de la MIGM de Buenos Aires para los años 1864-1867 ${ }^{56}$.

\subsection{Aporte de los regimientos al servicio de frontera}

De acuerdo con la información que presentamos en la Tabla 2, podemos observar una gran disparidad entre los regimientos que eran movilizados hacia la frontera. Para 1864, vemos que, de los 19 regimientos de Guardias Nacionales que existieron en la campaña bonaerense hasta 1866 (cf. Figura 1 en Anexos), solo registramos 12 proveyendo milicianos para el servicio de frontera: $\operatorname{los} \mathrm{N}^{\text {os }} 1,2,4,5,6,7,10,11,14$, 15, 17 y 18. De estos, tres pertenecían a la Frontera Norte ( ${ }^{\circ o s} 2,4$ y 5), cuatro a la Frontera Oeste $\left(\mathrm{N}^{o s} 1,6,7\right.$ y 18$)$, uno a la Frontera $\operatorname{Sud}\left(\mathrm{N}^{\circ} 10\right)$ y cuatro a la Frontera Costa Sud (Nos $11,14,15$ y 17). Del total, la primera recibió 174 guardias nacionales $(19,54 \%)$, la segunda $240(26,92 \%)$, la tercera $18(2,02 \%)$ y la cuarta $459(51,52 \%)$.

Además, sólo cuatro (los Nos $7,11,14$ y 17) aportaron cada uno más del $10 \%$ y sumados entre sí el $62,85 \%$ del total. Si profundizamos aún más el análisis, notamos que tres de estos cuatro regimientos pertenecían a la Frontera Costa Sud y que -como ya mencionamos- más de la mitad del total de los milicianos movilizados que fueron contabilizados en el estado general de 1864 residían en los partidos que integraban esa jurisdicción. Por último, al examinar el aporte individual de cada uno de los regimientos, se destaca la sobrecarga del $\mathrm{N}^{\circ} 17$, que registró casi el $30 \%$ del total de los guardias nacionales militarizados en abril de ese año.

Para 1865, se registra una cantidad de milicianos inferior, ya que el gobierno nacional intentaba suplantarlos por soldados regulares. Sólo siete estaban en la frontera entre febrero y marzo de 1865: $\operatorname{los} \mathrm{N}^{\circ \mathrm{s}} 2,3,8,13,17,19$ y la Guardia Nacional de Junín. De estos, cinco integraban la Frontera Norte ( ${ }^{\text {so }} 2,3,8,19$ y la Guardia Nacional de Junín), uno la Frontera Sud ( $\left.{ }^{\circ} 13\right)$ y uno la Frontera Costa Sud ( ${ }^{\circ}$ 17). Por lo tanto, la mayor parte de los guardias nacionales proveyeron su servicio de armas en la primera: 458, que representaban el $76,45 \%$. Por su parte, $108(18,03 \%)$ estuvieron en la tercera y sólo $33(5,51 \%)$ en la segunda. Al igual que en 1865 , el desequilibrio entre los regimientos fue muy prominente y los más exigidos fueron $\operatorname{los} \mathrm{N}^{\text {os }} 8,17$ y 19 , que en conjunto aportaron casi el $64 \%$ del total.

En 1866 se cuadruplica la cantidad de guardias nacionales registrados en la frontera bonaerense, alcanzando los 2.516 hombres, y se observa un enorme desbalance en lo que respecta a la provisión por regimientos. Además, se incrementó la cantidad de cuerpos que resguardaban la frontera (12 de 19). Al igual que en los años analizados anteriormente, el Regimiento $\mathrm{N}^{\circ} 17$ proporciona más del $22 \%$ de los milicianos. En esta ocasión, es superado por el $\mathrm{N}^{\circ} 6$, que suministró 595 hombres, que representaron el $23,65 \%$ del total. Por último, el $\mathrm{N}^{\circ} 16$ también se destacó, ya que registró 411 guardias nacionales, cubriendo el 16,33\% del total. Estos tres regimien-

56 Para este período, las MMGyM y la MIGM contienen los estados generales de los regimientos de la Guardia Nacional de la provincia de Buenos Aires de 1865 y 1867. Al mismo tiempo, especifican cuántos hombres fueron movilizados hacia la frontera por regimiento en 1864-1867, lo cual hace factible la elaboración de guarismos para analizar la militarización de los hombres adultos en edad militar. 
tos conformados por partidos fronterizos aglutinaron el 62,04\% (1.561 plazas) de la Guardia Nacional movilizada. Si a ello sumamos los milicianos del otro regimiento de frontera que se apuntaron en el estado general, el $\mathrm{N}^{\circ} 4$, obtenemos que, del total de los 2.516 hombres movilizados, $1.736(69 \%)$ fueron provistos por unidades conformadas por este tipo de distritos y sólo 780 (31\%) correspondieron a partidos de la campaña.

Tabla 2. Aporte por regimientos de la Guardia Nacional a la frontera (1864-1867) ${ }^{57}$

\begin{tabular}{|c|c|c|c|c|c|c|c|c|}
\hline \multirow{2}{*}{ Regimiento } & \multicolumn{2}{|c|}{$\mathbf{1 8 6 4}$} & \multicolumn{2}{|c|}{$\mathbf{1 8 6 5}$} & \multicolumn{2}{c|}{$\mathbf{1 8 6 6}$} & \multicolumn{2}{|c|}{$\mathbf{1 8 6 7}$} \\
\cline { 2 - 9 } & $\mathbf{n}^{\circ}$ & $\mathbf{9}$ & $\mathbf{n}^{\circ}$ & $\mathbf{\%}$ & $\mathbf{n}^{\circ}$ & $\mathbf{\%}$ & $\mathbf{n}^{\circ}$ & $\mathbf{\%}$ \\
\hline $\mathbf{1}$ & 16 & $1,79 \%$ & & & & & 45 & $2,75 \%$ \\
\hline $\mathbf{2}$ & 17 & $1,92 \%$ & 28 & $4,67 \%$ & & & 45 & $2,75 \%$ \\
\hline $\mathbf{3}$ & & & 87 & $14,53 \%$ & & & & \\
\hline $\mathbf{4}$ & 78 & $8,75 \%$ & & & 175 & $6,96 \%$ & 180 & $11 \%$ \\
\hline $\mathbf{5}$ & 79 & $8,87 \%$ & & & 215 & $8,54 \%$ & 190 & $11,61 \%$ \\
\hline $\mathbf{6}$ & 53 & $5,95 \%$ & & & 595 & $23,65 \%$ & 200 & $12,22 \%$ \\
\hline $\mathbf{7}$ & 105 & $11,78 \%$ & & & 30 & $1,19 \%$ & 71 & $4,34 \%$ \\
\hline $\mathbf{8} \mathbf{1 9}$ & & & $275^{58}$ & $45,91 \%$ & 49 & $1,95 \%$ & 96 & $5,86 \%$ \\
\hline $\mathbf{9}$ & & & & & 17 & $0,68 \%$ & 30 & $1,83 \%$ \\
\hline $\mathbf{1 0}$ & 18 & $2,02 \%$ & & & 120 & $4,77 \%$ & & \\
\hline $\mathbf{1 1}$ & 99 & $11,11 \%$ & & & $138^{59}$ & $5,48 \%$ & 50 & $3,05 \%$ \\
\hline $\mathbf{1 2}$ & & & & & & & & \\
\hline $\mathbf{1 3}$ & & & 33 & $5,51 \%$ & & & 80 & $4,89 \%$ \\
\hline $\mathbf{1 4}$ & 90 & $10,10 \%$ & & & & & 200 & $12,22 \%$ \\
\hline $\mathbf{1 5}$ & 4 & $0,45 \%$ & & & & & 50 & $3,05 \%$ \\
\hline $\mathbf{1 6}$ & & & & & 411 & $16,33 \%$ & & \\
\hline $\mathbf{1 7}$ & 266 & $29,86 \%$ & 108 & $18,03 \%$ & 555 & $22,06 \%$ & 150 & $9,15 \%$ \\
\hline $\mathbf{1 8}$ & 66 & $7,40 \%$ & & & 211 & $8,39 \%$ & 80 & $4,89 \%$ \\
\hline $\mathbf{2 0}$ & & & & & & & 70 & $4,28 \%$ \\
\hline $\mathbf{2 1}$ & & & & & & & & \\
\hline $\mathbf{2 2}$ & & & & & & & 100 & $6,11 \%$ \\
\hline Total & $\mathbf{8 9 1}$ & $\mathbf{1 0 0 \%}$ & $\mathbf{5 9 9}$ & $\mathbf{1 0 0 \%}$ & $\mathbf{2 . 5 1 6} \%$ & $\mathbf{1 0 0 \%}$ & $\mathbf{1 . 6 3 7} \%$ & $\mathbf{1 0 0 \%}$ \\
\hline
\end{tabular}

$57 \quad$ En este cuadro se excluyen los aportes de la Guardia Nacional de Bahía Blanca y Patagones. Fuente: elaboración propia en base a las MMGyM de 1864-1879 y a la MIGM de Buenos Aires de 1867 (AHPBA, Ministerio de Gobierno, año 1867, leg. 3, exp. 238).

58 Estos datos corresponden a los regimientos Nos 8 y 19 en conjunto. No diferenciamos el aporte de cada uno de ellos, ya que la documentación carece de esa precisión.

59 Estos datos corresponden a los regimientos Nos 11 y 15 en conjunto. No diferenciamos el aporte de cada uno de ellos, ya que la fuente carece de esa precisión.

60 De este total, también forman parte 68 guardias nacionales (correspondientes al 11,35\%) que estaban en servicio en Junín y que la fuente no especifica el regimiento del cual procedían. Según estimamos, pertenecían al mismo partido de Junín.

${ }^{61}$ Estos datos se extrajeron de la MMGyM de 1866. Se agregaron 540 guardias nacionales que se movilizaron a la frontera en el mes de noviembre de ese año, con el propósito de cubrir al igual número de milicianos que habían sido enviados a Cuyo a reprimir la "revolución de los colorados". Esta información proviene de la MIGM de Buenos Aires de 1867.

62 Estos datos se extrajeron de la MIGM de Buenos Aires de 1867. 
Por último, en el año 1867 se registran 879 guardias nacionales menos en la frontera. Se observan grandes disparidades con respecto a los años anteriores, en lo que respecta al modo en que los regimientos cubrieron las falencias del Ejército de Línea. En primer lugar, se registra una mayor cantidad de regimientos que proveyeron fuerzas a la frontera: 17 de los 22 que ya existían en 1867 (cf. Figura 2 en Anexos), en lugar de los 12 que manifestaba la Memoria anterior. En segundo lugar, se hace más equitativa la distribución de efectivos por regimiento: sólo existen cuatro por encima del 10\% (los Nos 4, 5, 6 y 14) y, de estos, ninguno alcanza el 13\%. En tercer lugar, la disparidad entre la campaña y la frontera se disipa e, incluso, revierte. Según la MIGM, los regimientos de la campaña proveyeron 1.007 guardias nacionales $(61,51 \%)$ y los de partidos fronterizos - $\mathrm{N}^{\mathrm{os}} 4,6,17$ y 22 - sólo $630(38,49 \%)$.

Pese a la relevancia de estos datos, debemos remarcar su carácter parcial. Corresponden a una "foto" de la militarización de la campaña bonaerense, que fue tomada en un/os determinado/s día/s de los meses de marzo o abril y, por lo tanto, no da cuenta de la dinámica del reclutamiento para la frontera. Más que cifras definitivas, aporta algunos números para estudiar la militarización, que no alcanza para denotar la totalidad del impacto del servicio de armas en los guardias nacionales de Buenos Aires. El estado general de la MMGyM de la Nación, que utilizamos para construir la Tabla 2, no registra los contingentes de guardias nacionales de los regimientos $\mathrm{N}^{\text {os }} 1$, 4,5 y 18 que fueron enviados a la frontera en $1865^{63}$, y del $\mathrm{N}^{\circ} 20$ que tuvo igual destino en $1866^{64}$. No obstante, consideramos que mostrar estos límites no hace desechables las conclusiones a las que arribamos, sino que las convierte en una base de datos para reconstruir el impacto de la militarización en la población rural bonaerense.

\subsection{Una medición de la militarización de los guardias nacionales}

De acuerdo con lo planteado por Charles Tilly, la nacionalización de las fuerzas militares implicó una invasión sin precedentes en las relaciones sociales cotidianas por parte del Estado ${ }^{65}$. En las tablas 3 y 4, evaluamos una de las variables que evidencian tal intromisión: el nivel de militarización al cual fueron sometidos los guardias nacionales bonaerenses para cumplir con el servicio de armas entre 1864 y 1867. Consideramos el total de la fuerza activa de la institución, que reunía a todos los ciudadanos argentinos casados que tuvieran entre 18 y 45 años o 50, inclusive, en el caso de los solteros ${ }^{66}$, y el impacto en cada uno de los regimientos.

Con respecto a la primera cuestión, observamos que el nivel de militarización de los hombres adultos de la campaña en edad militar tuvo directa correlación con el aporte anual de la Guardia Nacional para el servicio de frontera (cf. supra). En 1865, la provincia de Buenos Aires -con excepción de su ciudad capital-contaba con 25.376 guardias nacionales activos -entre jefes, oficiales y tropa-, repartidos entre caballería e infantería, aunque con un notable predominio de la primera. Por su parte,

Emilio Mitre a Benito Nazar. Junín, 2-III-1865 y Pedro Naón. San José de Flores, 30-V-1865. SHE, Frontera con los indios, año 1865 , docs. 2.881 y 2.977 .

64 Manuel Montes y Marull a Plácido López. Junín, 26-IV-1866. Archivo del coronel Dr. Marcos Paz [Argentina] (AMP), tomo V, 116-118, doc. 1.372.

65 Tilly, 1992: 175.

66 No incluimos a la milicia pasiva, ya que por lo general estaba exceptuada del servicio de frontera y solo se movilizaba en circunstancias extraordinarias. En ella revistaban los ciudadanos argentinos casados que superaran los 45 años de edad -50 en el caso de los solteros- y llegaran hasta los 60. 
en abril de 1867, se registraron 37.198 individuos enrolados en la Guardia Nacional activa, en las mismas condiciones reseñadas para el estado general de dos años antes.

Tabla 3. Militarización de los guardias nacionales por regimientos (1864-1866) ${ }^{67}$.

\begin{tabular}{|c|c|c|c|c|c|c|c|}
\hline \multirow{3}{*}{ Regimiento } & \multirow{3}{*}{$\begin{array}{c}\text { Guardia } \\
\text { Nacional } \\
\text { activa }^{68}\end{array}$} & \multicolumn{6}{|c|}{$\begin{array}{l}\text { Guardias Nacionales por regimientos } \\
\text { que fueron movilizados a la frontera }\end{array}$} \\
\hline & & \multicolumn{2}{|c|}{1864} & \multicolumn{2}{|c|}{1865} & \multicolumn{2}{|c|}{1866} \\
\hline & & $n^{\circ}$ & $\%$ & $n^{\circ}$ & $\%$ & $n^{\circ}$ & $\%$ \\
\hline 1 & 813 & 16 & $1,97 \%$ & & & & \\
\hline 2 & 1.211 & 17 & $1,4 \%$ & 28 & $2,31 \%$ & & \\
\hline 3 & 1.732 & & & 87 & $5,02 \%$ & & \\
\hline 4 & 1.551 & 78 & $5,03 \%$ & & & 175 & $11,28 \%$ \\
\hline 5 & 1.161 & 79 & $6,8 \%$ & & & 215 & $18,52 \%$ \\
\hline 6 & 1.306 & 53 & $4,06 \%$ & & & 595 & $45,56 \%$ \\
\hline 7 & 761 & 105 & $13,8 \%$ & & & 30 & $3,94 \%$ \\
\hline 8 y 19 & 2.534 & & & 275 & $10,85 \%$ & 49 & $1,93 \%$ \\
\hline 9 & 1.799 & & & & & 17 & $0,94 \%$ \\
\hline 10 & 734 & 18 & $2,45 \%$ & & & 120 & $16,35 \%$ \\
\hline 11 & 1.510 & 99 & $6,56 \%$ & & & $138^{69}$ & $6,73 \%$ \\
\hline 12 & 360 & & & & & & \\
\hline 13 & 1.143 & & & 33 & $2,89 \%$ & & \\
\hline 14 & 1.417 & 90 & $6,35 \%$ & & & & \\
\hline 15 & 542 & 4 & $0,74 \%$ & & & & \\
\hline 16 & 2.227 & & & & & 411 & $18,45 \%$ \\
\hline 17 & 2.139 & 266 & $12,44 \%$ & 108 & $5,05 \%$ & 555 & $25,95 \%$ \\
\hline 18 & 2.436 & 66 & $2,71 \%$ & & & 211 & $8,66 \%$ \\
\hline Total & 25.376 & 891 & $3,51 \%$ & $\mathbf{5 9 9}^{70}$ & $2,36 \%$ & $2.516^{71}$ & $9,91 \%$ \\
\hline
\end{tabular}

67 Fuente: elaboración propia en base a las MMGyM de 1864-1879 y a la MIGM de Buenos Aires de 1867 (AHPBA, Ministerio de Gobierno, año 1867, leg. 3, exp. 238).

68 Corresponde al año 1865. Se contabilizaron todos los individuos de la Guardia Nacional activa registrados en la categoría de jefes (coroneles, teniente coroneles, comandantes y sargentos mayores), oficiales (capitanes, tenientes $1^{\circ}$ y $2^{\circ}$ y alféreces $1^{\circ}$ y $2^{\circ}$ ) y tropa (portaestandartes, sargentos $1^{\circ}$ y $2^{\circ}$, cabos $1^{\circ}$ y $2^{\circ}$, tambores, trompas, músicos y soldados de caballería e infantería). Excluimos a los enrolados en la Guardia Nacional pasiva. En este cuadro no se consideran los aportes de la Guardia Nacional de Bahía Blanca y Patagones.

69 Estos datos corresponden a los regimientos Nos 11 y 15 en conjunto. No diferenciamos el aporte de cada uno de ellos, ya que la fuente carece de esa precisión.

70 De este total, también forman parte 68 guardias nacionales (correspondientes al 11,35\%) que estaban en servicio en Junín y que la fuente no especifica el regimiento del cual procedían. Según estimamos, pertenecían al mismo partido de Junín.

71 Estos datos se extrajeron de la MMGyM de 1866 y de la MIGM de Buenos Aires de 1867. 
Tabla 4. Militarización de los guardias nacionales por regimientos $(1867)^{72}$

\begin{tabular}{|c|c|c|c|}
\hline \multirow{2}{*}{ Regimiento } & \multirow{2}{*}{$\begin{array}{c}\text { Guardia } \\
\text { Nacional activa }^{73}\end{array}$} & \multicolumn{2}{|c|}{$\begin{array}{c}\text { Guardias nacionales incorporados } \\
\text { al Ejército }\end{array}$} \\
\hline & & $n^{\circ}$ & $\%$ \\
\hline 1 & 913 & 195 & $21,36 \%$ \\
\hline 2 & 1.233 & 217 & $17,60 \%$ \\
\hline 3 & 2.669 & 500 & $18,73 \%$ \\
\hline 4 & 1.873 & 180 & $9,61 \%$ \\
\hline 5 & 3.435 & 420 & $12,23 \%$ \\
\hline 6 & 2.321 & 200 & $8,63 \%$ \\
\hline 7 & 934 & 71 & $7,60 \%$ \\
\hline 8 & 1.531 & 252 & $16,46 \%$ \\
\hline 9 & 2.542 & 30 & $1,18 \%$ \\
\hline 10 & 782 & & \\
\hline 11 & 1.110 & 104 & $9,40 \%$ \\
\hline 12 & 778 & 34 & $4,37 \%$ \\
\hline 13 & 779 & 80 & $10,27 \%$ \\
\hline 14 & 2.002 & 476 & $23,78 \%$ \\
\hline 15 & 1.025 & 50 & $4,88 \%$ \\
\hline 16 & 2.637 & & \\
\hline 17 & 2.744 & 150 & $5,47 \%$ \\
\hline 18 & 2.031 & 80 & $3,94 \%$ \\
\hline 19 & 1.332 & 652 & $48,95 \%$ \\
\hline 20 & 880 & 160 & $18,18 \%$ \\
\hline 21 & 1.063 & & \\
\hline 22 & 2.033 & 100 & $4,92 \%$ \\
\hline Bahía Blanca & 214 & & \\
\hline Patagones & 337 & & \\
\hline Total & 37.198 & 3.951 & $10,62 \%$ \\
\hline
\end{tabular}

Según los registros de 1864 y 1865, fue escasa la población enrolada en la milicia activa que se movilizó a la frontera: 891 y 599, que representaban el 3,51\% y 2,36\% del total, respectivamente. Por su parte, en 1866 se registró una mayor cantidad de

72 Fuente: elaboración propia en base a las MMGyM de 1864-1879 y a la MIGM de Buenos Aires de 1867 (AHPBA, Ministerio de Gobierno, año 1867, leg. 3, exp. 238).

73 Se contabilizaron todos los individuos de la Guardia Nacional activa registrados en la categoría de jefes (coroneles, comandantes y sargentos mayores), oficiales (capitanes, tenientes $1^{\circ}$ y $2^{\circ}$ y alféreces $1^{\circ}$ y $2^{\circ}$ ) y tropa ( sargentos $1^{\circ}$ y $2^{\circ}$, cabos $1^{\circ}$ y $2^{\circ}$, trompas y soldados de caballería e infantería). Excluimos a los enrolados en la Guardia Nacional pasiva. 
milicianos en esa condición. La cifra asciende a 2.516 hombres, que computaban el 9,91\% de la Guardia Nacional activa de la campaña. Finalmente, en 1867 se registran 3.951 hombres incorporados al Ejército. En esta ocasión, la fuente no distingue los que estaban en la frontera bonaerense, en Paraguay o combatiendo a los federales en Cuyo. Este año, el nivel de militarización de los pobladores de la campaña aumentó al 10,62\%, triplicando y cuadruplicando los valores que recogimos para 1864 y 1865. De acuerdo con el planteo de Florencia Carlón para años anteriores, estos guarismos no evidenciarían un estado de guerra -caracterizado por un conflicto a "gran escala" que involucrara a la totalidad de la sociedad indígena y bonaerense-, sino más bien una situación de enfrentamiento latente que coexistía con relaciones diplomáticas y de intercambio ${ }^{74}$.

No obstante, si realizamos un análisis más detallado de la información que volcamos en las tablas 3 y 4, vemos que los porcentajes generales de la población militarizada de la campaña no siempre se correspondieron con las situaciones particulares de cada regimiento, por lo que se requiere de un ejercicio interpretativo más profundo que nos permita dar cuenta de las especificidades.

Por un lado, como mostramos en el apartado anterior, a no todos los regimientos se les exigió el servicio de frontera en la misma proporción. Si bien la totalidad de estos fueron movilizados en 1864-18676, el Regimiento $\mathrm{N}^{\circ} 17$ hizo un servicio regular durante los cuatro años, otros durante tres años $-\operatorname{los} \mathrm{N}^{\text {os }} 2,4,5,6,7,8,11,18$ y 19-, algunos durante dos años $-\operatorname{los} \mathrm{N}^{\mathrm{os}} 1,3,9,10,13,14$ y $15-\mathrm{y}$, finalmente, el resto sólo una vez -los №s 12,16 y 20.

Por otro lado, se observa que algunos regimientos fueron muy exigidos y que el índice de militarización de sus integrantes no se equipara con los guarismos generales que expusimos, los cuales solo superaron el 10\% en una ocasión. Vemos que, en abril de 1867, el Regimiento $\mathrm{N}^{\circ} 19$ tenía movilizado el 48,95\% de sus guardias nacionales activos ${ }^{75}$. Además, que -sumados los porcentajes interanuales de los estados generales de 1864-1867- se reclutó para la frontera una cantidad equivalente al $55 \%$ de los milicianos enrolados en este Regimiento; al 58,25\% del $\mathrm{N}^{\circ} 6$; al 48,91\% del $\mathrm{N}^{\circ} 17$; al $37,55 \%$ del $\mathrm{N}^{\circ} 5$ y al 30,13\% del $\mathrm{N}^{\circ} 14$. Luego se destaca un segundo grupo de regimientos que tuvieron un índice de militarización que varía entre el $20 \%$ y $30 \%: \operatorname{los} \mathrm{N}^{\circ} 4(25,9 \%), \mathrm{N}^{\circ} 7(25,34 \%), \mathrm{N}^{\circ} 3(23,75 \%), \mathrm{N}^{\circ} 1(23,3 \%), \mathrm{N}^{\circ}$ $11(22,8 \%), \mathrm{N}^{\circ} 8(21,9 \%)$ y $\mathrm{N}^{\circ} 2(21,3 \%)$. Posteriormente, encontramos cinco regimientos con guarismos que varían entre el 10\% y 20\%:10-20\%: los $\mathrm{N}^{\circ} 10(18,8 \%)$, $\mathrm{N}^{\circ} 16(18,45 \%), \mathrm{N}^{\circ} 20(18,8 \%), \mathrm{N}^{\circ} 18(15,31 \%)$ y $\mathrm{N}^{\circ} 13(13,16 \%)$. Y, por último, registramos cuatro regimientos que movilizaron un porcentaje escaso de guardias

74 Carlón, 2014: 252-253. Con anterioridad, otros autores han medido la presión militar que sufrieron los hombres adultos en épocas y escenarios diferentes. Para 1818, Alejandro Rabinovich registró que el 37\% de los milicianos del Río de la Plata fueron movilizados para la guerra (Rabinovich, 2012: 36-37). Por su parte, Roberto Schmit ha mostrado altos índices de movilización de la milicia de Entre Ríos en la primera mitad del siglo XIX. Observa un altísimo porcentaje de participación de hombres mayores de 14 años de edad, que estima entre el $35 \%$ y $45 \%$ para la década de 1820 y entre el $60 \%$ y $70 \%$ para los enfrentamientos de mediados de siglo, que derivaron en el combate de "Caseros" (Schmit, 2004: 177). A su vez, Sol Lanteri demostró que el 53\% de los hombres nativos entre 15 y 60 años de edad que residían en el partido fronterizo de Azul se movilizaron para defender al gobernador Juan Manuel de Rosas en esa batalla (Lanteri, 2011: 300-301).

75 Estimamos que los 652 guardias nacionales del Regimiento $\mathrm{N}^{\circ} 19$ estaban en Paraguay, integrando el Ejército de Operaciones que combatía en ese país en alianza con las fuerzas brasileñas y uruguayas. Decreto sobre reclutamiento de la Guardia Nacional de frontera de acuerdo al sorteo. Buenos Aires, 10-VIII-1869. AHPBA, Ministerio de Gobierno, año 1869, leg. 11, exp. 772. 
nacionales que estaban enrolados en la milicia activa: los $\mathrm{N}^{\text {os }} 15,22,12$ y 9 , que solo aportaron el 5,62\%, 4,92\%, 4,37\% y 2,12\%, respectivamente.

Por último, consideramos pertinente remarcar que los guarismos a los cuales arribamos en este apartado se deben tomar como números y/o porcentajes provisorios, ya que solo muestran la cantidad de guardias nacionales que estaban movilizados en un momento determinado -los meses de marzo o abril-y no la totalidad de los reclutados a lo largo del año. Por tal motivo, más que una medición fidedigna de la militarización de los hombres adultos de la campaña bonaerense en edad de tomar las armas, representa un índice de mínima para ver su impacto en la sociedad.

Según las disposiciones vigentes, los guardias nacionales debían brindar su servicio de armas en la frontera por el término de seis meses y, luego, ser relevados. Una primera interpretación de esto, nos llevaría a pensar que tendríamos que duplicar la cantidad de hombres movilizados que se registraron en los estados generales para acercarnos a los que lo hicieron por el término de un año, por lo que obtendríamos un índice de militarización mucho más alto por regimiento del que computamos. No obstante, se cometería un grave error metodológico por varios motivos. Primero, los guardias nacionales movilizados de modo circunstancial, por días o semanas, no siempre quedaban registrados en las listas de revistas. Segundo, algunos excedieron los seis meses de servicio, al revistar por más de un año, a causa de la arbitrariedad de los jefes de frontera y de la escasa capacidad de reclutamiento de los comandantes locales. Tercero, en aquellas ocasiones donde las plazas en la frontera pudieran ser cubiertas con fuerzas regulares, los milicianos eran licenciados sin necesidad de ser relevados por otros. Y, finalmente, producto de la gran movilidad territorial de la población bonaerense, los hombres adultos en edad militar no permanecieron de por vida enrolados en un mismo regimiento, sino que fueron cambiando de unidad miliciana a medida que se trasladaban de un distrito a otro.

\section{Conclusiones}

En este artículo estudiamos cómo el Estado nacional argentino logró monopolizar el control de las fuerzas armadas en la frontera sur del país, a partir de analizar el aporte de cada una de las fuerzas armadas al sistema militar ofensivo/defensivo de la frontera y la militarización de los hombres adultos de la campaña bonaerense sujetos a reclutamiento en la Guardia Nacional activa.

En la primera parte procuramos complejizar la noción que existe en la historiografía con respecto al declive constante de las milicias a medida que se consolidaba el Ejército de Línea y el Estado nacional. Planteamos que la Guardia Nacional no se debe analizar de modo uniforme durante los años de centralización de poder estatal y sin tener en cuenta la evolución y las transformaciones por las cuales atravesó, que estuvieron vinculadas de modo directo con aquél proceso. Demostramos que su accionar estuvo directamente ligado al Ejército regular. Cuando las fuerzas de este último eran insuficientes, la Guardia Nacional proveía sus hombres para la defensa de la frontera y, a medida que aquél se iba consolidando, la suplantó en las tareas que desarrollaba.

En este sentido, considerando una serie de dificultades metodológicas, mostramos tres períodos definidos. En 1862-1865, el gobierno nacional fue reduciendo de forma progresiva la exigencia a la Guardia Nacional de campaña de la provincia de 
Buenos Aires para el servicio de frontera, a causa de que el Ejército de Línea se fue liberando de los conflictos en el Interior del país y haciéndose cargo de la guarda fronteriza. Durante 1865-1871, la Guardia Nacional suplió las falencias del Ejército de Línea, debido a que éste último participó de campañas militares en diversos lugares del país y en Paraguay. Este período representó la coyuntura en la cual transitó por el momento de mayor participación en la defensa de la frontera, ya que se la utilizó de un modo intensivo, complementando y/o suplantando al Ejército regular en tareas que no le correspondían. Desde 1872 se fue afirmando y consolidando el Ejército de Línea, a la par que se reducía el aporte de la Guardia Nacional y, por momentos, se incrementaba el de los lanceros indígenas. En estos años, la Guardia Nacional atravesó por su etapa de declive. Desarrolló sus funciones bajo la completa supremacía del Ejército regular y fue licenciada de forma definitiva del servicio de frontera en 1878. Sin embargo, advertimos que la centralización del poder militar en manos del Estado nacional no fue lineal, ya que fue muy requerida en la frontera en los años 1874, 1876 y 1877, al movilizar una gran cantidad de milicianos con el propósito de dar respuesta a las exigencias militares.

En la segunda parte examinamos el impacto que tuvo en los hombres adultos de la campaña bonaerense en edad militar la incapacidad del Estado nacional para consolidar un Ejército regular que se pudiera hacer cargo del sistema militar ofensivo/ defensivo de la frontera. La militarización de los guardias nacionales enrolados en la milicia activa fue una consecuencia directa de ello.

Por un lado, evaluamos si el servicio de frontera que se les exigió fue equitativo o si, en cambio, los regimientos fronterizos recibieron mayor presión, tal como dieran cuenta algunos informes de los hombres de época. A partir de un análisis exhaustivo para el período 1864-1867, mostramos que la provisión de guardias nacionales para la frontera no se produjo de forma equitativa para todos los regimientos de la provincia de Buenos Aires, ya que las unidades fronterizas sufrieron mayor presión reclutadora que las restantes de la campaña y, dentro de estos, algunos, como los $\mathrm{N}^{\mathrm{os}} 6,16$ y 17, fueron más exigidos. Aunque, también, vimos que para 1865 los regimientos Nos 8 y 19, que pertenecían a la campaña, fueron muy requeridos. Para el año 1867 notamos una situación diferente que matiza, en parte, estas aseveraciones. Se registra una mayor presencia de toda la campaña y, como consecuencia, una considerable simetría en la militarización de la población rural bonaerense.

Por otro lado, medimos el índice de militarización de los guardias nacionales que estuvieron sujetos al servicio de armas en la frontera. Al analizar el aporte anual del conjunto de la Guardia Nacional de campaña en relación a la totalidad de los hombres enrolados en la milicia activa, notamos dos momentos en el período que examinamos. En 1864 y 1865 se movilizó una cantidad de milicianos que osciló entre el 2,3\% y el 3,5\%, mientras que en 1866 y 1867 esa cifra aumentó al 9,9\% y 10,6\%, respectivamente. Al profundizar el estudio por regimientos, vimos que algunos de ellos, como los $\mathrm{N}^{\text {os }}$ 5, 6, 14, 17 y 19, fueron muy exigidos. Además, observamos que algunos cuerpos no recibieron la misma presión militar que aquellos y, por lo tanto, no fueron afectados en gran medida por el conflicto fronterizo y la insuficiencia del Ejército de Línea. De esta forma, podemos concluir que la militarización de los guardias nacionales de la campaña bonaerense fue inequitativa y desigual. En este marco, cobran sentido las resistencias y las estrategias evasivas que implementaron como respuesta al servicio de frontera, así como las políticas de control social que llevaba a cabo el Estado para evitarlas. 
La movilización ordinaria de contingentes y de guardias nacionales de forma momentánea fue algo recurrente en la historia de la Guardia Nacional de campaña de la provincia de Buenos Aires entre 1862 y 1878. Sin duda, ello constituyó el principal aporte de la institución a la construcción y consolidación del Estado nacional. Este último siguió dependiendo de la predisposición del gobernador y los poderes locales para cubrir el servicio de armas en la frontera, a causa de la insuficiencia del Ejército de Línea, que recién se pudo suplir en parte una vez entrado el año 1878. Por tal motivo, en este aspecto particular, la Guardia Nacional puede ser considerada como un instrumento del Estado nacional para su consolidación, más que un resabio que conspiraba contra ello y que debía abolir si quería constituirse como tal.

No obstante, la complejidad de esta milicia, que vivió determinada por las disputas políticas rioplatenses de la segunda mitad del siglo XIX y sujeta a los poderes locales, nos impide concluir que fue un "brazo armado" del Estado nacional. Serán necesarias nuevas investigaciones que examinen la participación política de los regimientos y el rol de los comandantes en la organización de esta fuerza para que, sumados a los que ya existen, nos ilustren una imagen más fidedigna y fehaciente del proceso de centralización de las fuerzas armadas decimonónicas en manos del Estado nacional.

\section{Referencias bibliográficas}

Alemano, María Eugenia - Carlón, Florencia. "Prácticas defensivas, conflictos y autoridades en la frontera bonaerense. Los pagos de Magdalena y Pergamino (17521780)". Anuario del Instituto de Historia Argentina, n 9 (2009), 15-42.

Alonso, Paula - Bragoni, Beatriz (eds.). El sistema federal argentino. Debates y coyunturas (1860-1910). Buenos Aires: Edhasa, 2015.

Barba, Fernando. Los autonomistas del 70. Auge y frustración de un movimiento provinciano con vocación nacional. Buenos Aires entre 1868 y 1878 . Buenos Aires: Ed. Pleamar, 1976.

- Frontera ganadera y guerra con el indio. La Plata: Editorial de la UNLP, 1997.

Barbuto, Lorena. "Estado Nación, frontera y milicias: de avances y resistencias. Córdoba, 1860-1870". Memoria Americana, n 17 (2009), 213-239.

Barros, Álvaro. Fronteras y territorios federales de las pampas del sur [1872]. Buenos Aires: Solar/Hachette, 1957.

Bragoni, Beatriz - Míguez, Eduardo (coords.). Un nuevo orden político. Provincias y Estado Nacional, 1852-1880. Buenos Aires: Biblos, 2010.

Buchbinder, Pablo. Caudillos de pluma y hombres de acción. Estado y política en Corrientes en tiempos de la organización nacional. Buenos Aires: Prometeo Libros-UNGS, 2004.

Canciani, Leonardo. "La negociación del servicio de frontera en la Guardia Nacional de campaña. Buenos Aires (1865-1870)". TEFROS, vol. 11 (2013), 1-25. Disponible en www.hum.unrc.edu.ar/ojs/index.php/tefros/article/view/261/242.

— "Resistencia a la obligación de armarse. Reclutamiento y servicio miliciano en la Guardia Nacional de frontera. Buenos Aires, 1852-1879". Memoria Americana, no 22 (2014), 33-63. Disponible en http://ppct.caicyt.gov.ar/index.php/memoriaamericana/article/view/3593/4455. 
- Frontera, militarización y política armada. La Guardia Nacional de la Provincia de Buenos Aires durante la construcción del Estado nacional (1852-1880). La Plata: AAAHPBA, 2017.

Carlón, Florencia. "Repensando los malones del siglo XVIII en la frontera de Buenos Aires". En Gobierno, justicias y milicias. La frontera entre Buenos Aires y Santa Fe (1720-1830), coordinado por Gabriel Barriera, Darío - Osvaldo Fradkin, Raúl. La Plata: Edulp, 2014, 251-275.

Comando en Jefe del Ejército. Reseña histórica y orgánica del Ejército Argentino. Buenos Aires: Círculo Militar, 1971-1972.

Domínguez, Ercilio. Colección de leyes y decretos militares concernientes al Ejército y Armada de la República Argentina de 1810 á 1896, vol. 2. Buenos Aires: Compañía Sud-Americana del Billetes de Banco, 1898.

Ébelot, Alfred. Frontera Sur. Recuerdos y relatos de la Campaña del Desierto (18751879). Buenos Aires: Editorial Kraft, 1968.

Fuente, Ariel de la. Los hijos de Facundo. Caudillos y montoneras en la provincia de La Rioja durante el proceso de formación del Estado nacional argentino (18531870). Buenos Aires: Prometeo Libros. 2007.

Gambetti, Nadia. "Soldados indígenas en la frontera de Buenos Aires (1862-1876)". Tesis de Licenciatura, Universidad Nacional de Quilmes, 2012.

Garavaglia, Juan Carlos. "Ejército y milicia: los campesinos bonaerenses y el peso de las exigencias militares, 1810-1860”. Anuario IEHS, n 18 (2003), 153-187.

Gayol, Víctor. "Las milicias nacionales en la construcción del Estado-Nación en España e Hispanoamérica, siglo XIX: hacia un balance historiográfico". En Las milicias del rey de España. Sociedad, política e identidad en las Monarquías Ibéricas, coordinado por Ruiz Ibáñez, José Javier. Madrid: FCE - Red Columnaria, 2009, 460-480.

Halperin, Tulio. "Revolutionary militarization in Buenos Aires, 1806-1815". Past and Present, $\mathrm{n}^{\circ} 40$ (1968), 84-107.

- Proyecto y construcción de una nación (Argentina 1846-1880). Caracas: Biblioteca de Ayacucho, 1980.

Lanteri, Sol. Un vecindario federal. La construcción del orden rosista en la frontera sur de Buenos Aires (Azul y Tapalqué). Córdoba: Centro de Estudios Históricos, 2011.

Literas, Luciano. "Milicias y fronteras en la formación del Estado argentino. La regulación de la Guardia Nacional de Buenos Aires (1852-1880)". Avances del CESOR, $\mathrm{n}^{\circ} 9$ (2012), 9-32. Disponible en www.ishir-conicet.gov.ar/archivos/ avances9.pdf, fecha de última consulta: 3-7-2015.

Macías, Flavia. "Guardia Nacional, ciudadanía y poder en Tucumán, Argentina (1850-1880)". Revista Complutense de Historia de América, vol. 27 (2001): 131161.

— “Armas y política en el norte argentino. Tucumán en tiempos de la organización nacional". Tesis Doctoral, Universidad Nacional de La Plata, 2007.

- Armas y política en la Argentina. Tucumán, siglo XIX. Madrid: Consejo Superior de Investigaciones Científicas, 2014.

Macías, Flavia - Sabato, Hilda. "La Guardia Nacional: Estado, política y uso de la fuerza en la Argentina de la segunda mitad del siglo XIX". PolHis, $\mathrm{n}^{\circ}$ 11-1 (2013): 70-81. Disponible en http://historiapolitica.com/datos/boletin/Polhis11 MACIASSABATO.pdf.

Míguez, Eduardo. "Guerra y orden social en los orígenes de la Nación Argentina, 
1810-1880". Anuario IEHS, $\mathrm{n}^{\circ} 18$ (2003), 17-38.

Olmedo, Ernesto. Militares de frontera. Fuertes, ejércitos y milicias en la frontera sur de Córdoba 1852-1869. Río Cuarto: UNRC, 2009.

Oszlak, Oscar. La formación del Estado argentino. Orden, progreso y organización nacional [1982]. Buenos Aires: Planeta, 1997.

Paz, Gustavo. "El gobierno de los 'conspicuos': familia y poder en Jujuy, 18531875". En La vida política en la Argentina del siglo XIX. Armas, voces y votos, compilado por Sabato, Hilda - Lettieri, Alberto. Buenos Aires: Fondo de Cultura Económica, 2003, 223-242.

Poggi, Rinaldo. Álvaro Barros en la Frontera Sur. Contribución al estudio de un argentino olvidado. Buenos Aires: Fundación Nuestra Historia, 1997.

- Los Gobernadores de Buenos Aires y la Guardia Nacional, 1862-1874. Buenos Aires: Fundación Nuestra Historia, 2000.

Quintián, Juan Ignacio. "Una Aristocracia Republicana. La formación de la elite Salteña, 1850-1870". Tesis Doctoral, Universidad de San Andrés, 2012.

Rabinovich, Alejandro. "La militarización del Río de la Plata, 1810-1820. Elementos cuantitativos y conceptuales para un análisis". Boletín del Instituto de Historia Argentina y Americana "Dr. Emilio Ravignani", n 37 (2012), 11-42.

Ratto, Silvia. "Soldados, milicianos e indios de "lanza y bola'. La defensa de la frontera bonaerense a mediados de la década de 1830". Anuario IEHS, n 18 (2003), 123-152.

— "Estado y cuestión indígena en las fronteras de Chaco y La Pampa (1862-1880)". Revista de Ciencias Sociales, $\mathrm{n}^{\circ} 20$ (2011), 7-27. Disponible en www.unq.edu.ar/ advf/documentos/5138b73a7c40e.pdf.

Rock, David. La construcción del Estado y los movimientos políticos en la Argentina, 1860-1916. Buenos Aires: Prometeo Libros, 2006.

Rouquié, Alain. El Estado militar en América Latina. Buenos Aires: Emecé Editores, 1984.

Sabato, Hilda. "Cada elector es un brazo armado'. Aportes para un estudio de las milicias en la Argentina decimonónica". En Las escalas de la historia comparada. Dinámicas sociales, poderes políticos y sistemas jurídicos, coordinado por Bonaudo, Marta - Reguera, Andrea - Zeberio, Blanca. Buenos Aires: Miño y Dávila, 2008a, 105-124.

- Buenos Aires en armas. La revolución de 1880. Buenos Aires: Siglo XXI Editores, 2008b.

- Historia de la Argentina, 1852-1890. Buenos Aires: Siglo XXI Editores, 2012.

Schmit, Roberto. Ruina y resurrección en tiempos de guerra. Sociedad, economía $y$ poder en el Oriente entrerriano posrevolucionario 1810-1852. Buenos Aires: Prometeo Libros, 2004.

Tamagnini, Marcela - Pérez Zavala, Graciana - Olmedo, Ernesto. "Los ranqueles reducidos en la frontera del Río Quinto durante la década de 1870: su incorporación al Ejército Nacional". En Las sociedades de los paisajes áridos y semiáridos del centro-oeste argentino, compilado por Martini, Yoli - Pérez Zavala, Graciana Aguilar, Yanina. Río Cuarto: Editorial de la UNRC, 2009, 295-311.

Tilly, Charles. Coerción, capital y los Estados europeos, 990-1990. Madrid: Alianza Editorial, 1992.

Walther, Juan Carlos. La conquista del desierto. Buenos Aires: Eudeba, 1964. 


\section{Anexos}

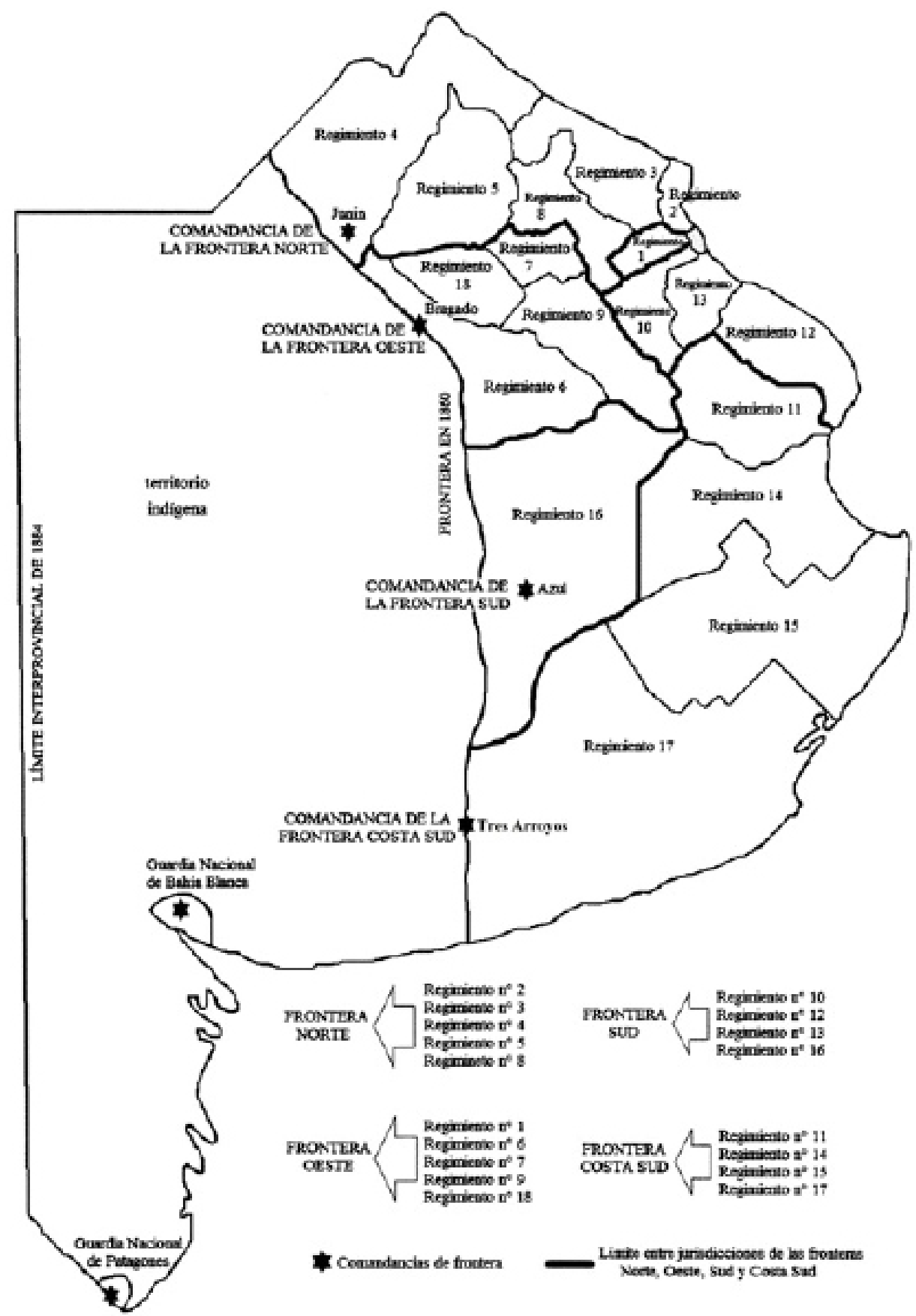

Figura 1. Regimientos de la Guardia Nacional de campaña de Buenos Aires (1864-1866) ${ }^{76}$

76 Fuente: elaboración propia en base a Mapa de la Provincia de Buenos Aires elaborado por José Toscano, 1882 (AGN, Mapoteca, II-121). 


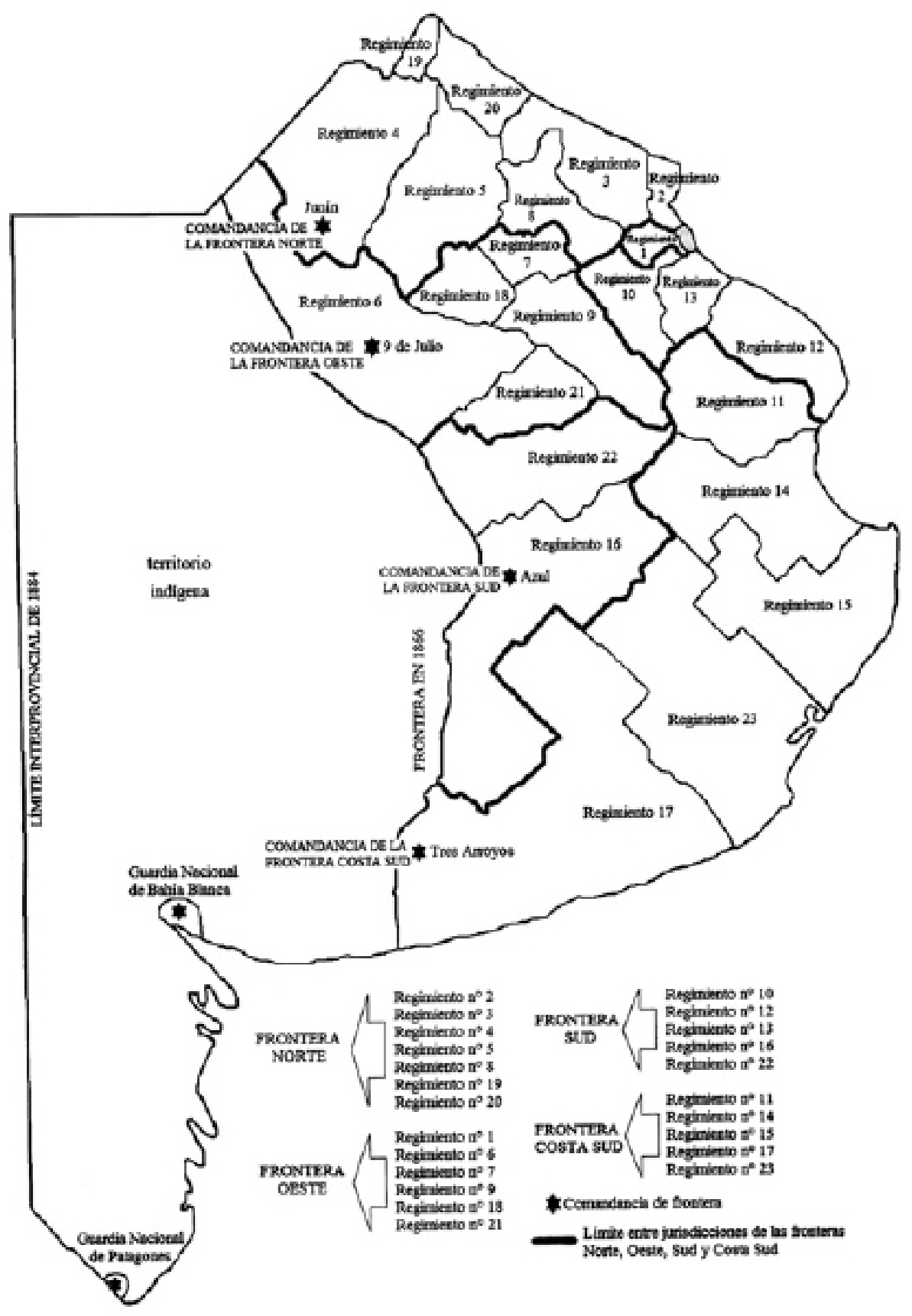

Figura 2. Regimientos de la Guardia Nacional de campaña de Buenos Aires (1866-1867)77

77 Fuente: elaboración propia en base a Mapa de la Provincia de Buenos Aires elaborado por José Toscano, 1882 (AGN, Mapoteca, II-121). 